\title{
Pulmonary Rehabilitation in Patients Recovering from COVID-19: Authors' Reply
}

\author{
Elisabetta Zampogna ${ }^{a}$ Mara Paneroni ${ }^{b}$ Michele Vitacca ${ }^{b}$ \\ Nicolino Ambrosinoc \\ alstituti Clinici Scientifici Maugeri, Respiratory Rehabilitation of the Institute of Tradate, IRCCS, Tradate, Italy; \\ bIstituti Clinici Scientifici Maugeri, Respiratory Rehabilitation of the Institute of Lumezzane, IRCCS, Brescia, Italy; \\ Istituti Clinici Scientifici Maugeri, Respiratory Rehabilitation of the Institute of Montescano, IRCCS, Milan, Italy
}

\begin{abstract}
And it's a hard, and it's a hard, it's a hard, and it's a hard, And it's a hard rain's a-gonna fall Bob Dylan
\end{abstract}

Dear Editor,

We thank Polastri for his interest [1] in our article [2]. He raises very important issues regarding research on and at the time of COVID-19: rehabilitation of survivors and the reliability of publications in the field.

The COVID-19 pandemic has been associated with a high index of publication, leading to a "paperdemic" [3]. Especially during the first wave of the pandemic, most of the publications reported results of observational, retrospective, uncontrolled studies or case reports with scientific limitations outlined by the author in the letter, leading to premature conclusions, mainly on the effects of drug management [4], and also to high level of retractions [5].

In addition to the impairment in respiratory function [6], a high prevalence of impairment in physical performance is reported in COVID-19 survivors, who may suffer from fatigue or muscle weakness, exercise-induced dyspnea, sleep difficulties, anxiety, and/or depression up to 6 months after acute infection [7, 8]. Clinical indications and modalities of pulmonary rehabilitation have been proposed by international guidelines and recommendations based on expert opinion and not on data $[9$, 10]. Information are based on retrospective, observational, or uncontrolled studies like ours [2].

Retrospective studies have limitations, such as missing data, and results of uncontrolled studies may be difficult to interpret because we can suppose a positive effect in the long-term follow-up of patients without a rehabilitative intervention. Nevertheless, a control population not performing any activity would be unethical, given the undisputed benefits of pulmonary rehabilitation or simple physical activity. Beyond these limitations, we cannot wait for well-designed randomized controlled trials to be published before starting interventions in daily clinical practice, as the number of COVID-19 patients increases rapidly every day. Therefore, despite the limitations of the retrospective uncontrolled design, we are confident that our article [2] may be useful for the scientific community, leading to the conclusion that such programs should be a main component of the management of these patients [11]. 
The unavoidable consequence is the need for validated outcome measures using safe equipment and procedures [12] to evaluate the short- and long-term consequences of COVID-19. Standardization of batteries of measures would allow us to make comparisons among studies and different follow-up time-points. Given the difficulties in performing controlled studies at present, the outcome measures should be validated and supported by reference values.

In conclusion, we totally agree with Polastri that rehabilitation should be 1 main corner of the comprehensive management of these patients. We need more studies on tolerance and short- and long-term effects of programs. We need standardized and common outcome measures to compare results among studies.

\section{Conflict of Interest Statement}

The authors have no conflicts of interest to declare.

\section{Funding Sources}

No funding was received.

\section{Author Contributions}

Elisabetta Zampogna, Mara Paneroni, Michele Vitacca, and Nicolino Ambrosino equally contributed to the writing of the manuscript and approved the version presented.

\section{References}

1 Polastri M. Increasing knowledge on postacute rehabilitation in COVID-19. Respiration. 2021.

2 Zampogna E, Paneroni M, Belli S, Aliani M, Gandolfo A, Visca D, et al. Pulmonary Rehabilitation in Patients Recovering from COVID-19. Respiration. 2021;100(5):416-22.

3 Dinis-Oliveira RJ. COVID-19 research: pandemic versus "paperdemic", integrity, values and risks of the speed science. Forensic Sci Res. 2020;5(2):174-87.

4 Cortegiani A, Ippolito M, Greco M, Granone V, Protti A, Gregoretti C, et al. Rationale and evidence on the use of tocilizumab in COVID-19: a systematic review. Pulmonology. 2021 Jan;27(1):52-66.

5 Boschiero MN, Carvalho TA, Marson FAL. Retraction in the era of COVID-19 and its influence on evidence-based medicine: is science in jeopardy? Pulmonology. 2021 Mar; 27(2):97-106
6 Torres-Castro R, Vasconcello-Castillo L, Alsina-Restoy X, Solis-Navarro L, Burgos F, Puppo $\mathrm{H}$, et al. Respiratory function in patients post-infection by COVID-19: a systematic review and meta-analysis. Pulmonology. 2020 Nov 25;S2531-0437(20):30245-2.

7 Paneroni M, Simonelli C, Saleri M, Bertacchini L, Venturelli M, Troosters T, et al. Muscle strength and physical performance in patients without previous disabilities recovering from COVID-19 pneumonia. Am J Phys Med Rehabil. 2021;100(2):105-9.

8 Huang C, Huang L, Wang Y, Li X, Ren L, Gu $\mathrm{X}$, et al. 6-month consequences of COVID-19 in patients discharged from hospital: a cohort study. Lancet. 2021;397(10270):220-32.
9 Vitacca M, Carone M, Clini EM, Paneroni M, Lazzeri M, Lanza A, et al. Joint statement on the role of respiratory rehabilitation in the COVID-19 crisis: the Italian position paper. Respiration. 2020;99(6):493-9.

10 American Thoracic Society. Report of an ad hoc international task force on early and short-term rehabilitative interventions in COVID-19 survivors; 2020. Available at (Accessed May, 26, 2021)

11 Winck JC, Ambrosino N. COVID-19 pandemic and non invasive respiratory management: every goliath needs a David. An evidence based evaluation of problems. Pulmonology. 2020 Jul-Aug;26(4):213-20.

12 Ippolito M, Vitale F, Accurso G, Iozzo P, Gregoretti C, Giarratano A, et al. Medical masks and respirators for the protection of healthcare workers from SARS-CoV-2 and other viruses. Pulmonology. 2020 Jul-Aug;26(4):204-12. 